International Journal of Engineering \& Technology, $7(3.29)(2018) 107-109$
SPC
Snternational Journal of Engineering \& Technology
Website: www.sciencepubco.com/index.php/IJET
Research paper

\title{
Nullpest: a mobile application of agricultural pest locator using sonar sensor set-up
}

\author{
Cortez Dan Michael $\mathrm{A}^{1 *}$, Molina Charito $\mathbf{M}^{2}$, Abante Marmelo $\mathbf{V}^{3}$, Santos Myra $\mathrm{S}^{4}$, Sarmiento Marygin $\mathbf{E}^{1}$ \\ ${ }^{1}$ College of Information Technology Education, College of Saint John Paul II Arts and Sciences \\ ${ }_{2}^{2}$ Information Technology Department, Pamantasan ng Lungsod ng Maynila \\ ${ }^{3}$ College of Information Technology Education, World Citi Colleges-Quezon City \\ ${ }^{4}$ College of Computer Studies, Tomas Claudio Colleges \\ *Corresponding authorE-mail: dan.cortez@yahoo.com.
}

\begin{abstract}
Philippines have already achieved its highest peak when it comes to substantive agricultural activities. The country has been one of the most leading distributors of agricultural crops most especially the rice commodity all throughout the world. With this, it can be concluded that agriculture is one important factor that affects the Philippines' economy, thus, it must be given thorough attention and importance not only by the country's government but also its constituents. There are inevitable factors that affects agricultural yield which results to rapid decrease of crop activities resulting to a devastating loss to the Philippine farmers, one of which is the existence of agricultural pest. These destructive pest gives fatal damage to agricultural crops by thriving its nutrients resulting to agricultural loss. Considering this, the aim of the study is to aid and help farmers locate such agricultural pest particularly on the rice commodity, give pesticide monitoring in order to limit pesticide usage that gives possible health risk to consumers, and lastly give pest information to its user particularly on farmers. With the combination of a Mobile Application and Arduino device all of this will become possible.
\end{abstract}

Keywords: Use about five key words or phrases in alphabetical order, Separated by Semicolon.

\section{Introduction}

Philippines is one of the world's "mega diversity" country when it comes to agriculture.

It is the 8th largest rice producer in the world, accounting for $2.8 \%$ of global rice worldwide. Aside from rice, there are corn, sugarcane, abaca, coconut, and fruits which are also well-known crops that the Philippines is abundant with. Thus, agriculture is important for both to human necessity and the country's economy.

Nowadays, various factors that severely affect our agriculture includes drastic climate change, sterility of soil cause by natural calamities, and especially invasion as well as infestation of pest in agricultural fields. These agricultural pests are destructive insects thriving on food, livestock, and especially agricultural crops. Moreover, they could ruin a whole season's worth of planting and careful cultivation leading to food and financial loss. Millions of pesos and huge hectares of land planted by rice, corn, and other vegetables are severely affected by these destructive pests.

There are certain methods that are present today to locate, eliminate or avoid these destructive pests. Some are by means of natural way to determine if a certain crop is infected with pests; an individual may manually inspect leaves from plants to identify the gravity of infestation. Other uses expensive apparatus to find which pests infects the most. In terms of avoidance, farmers use crop rotation method to disrupt the larva growth of insect, thus, a complete eradication, if not minimize the infestation. Agriculturists or farmers also uses the artificial way, which is to operate farms with the help of chemical abundant pesticides. These pesticides may harm the environment by altering soil composition to make it hard for pests to live in. While proven successful the utilization of it produces consequences, it also affects the crops quality. Surface of crops may accumulate small portions of pesticides since the crop also comes from the ground. It may also harm farmer's health since inhalation may occur while performing the task, same as for the consumer. There were cases that crops which came from farms that uses pesticide were processed directly making no place for cleaning.

By developing a combination of software and hardware that could determine the location of pests infesting agricultural crops, agriculturist can ensure adequate control measures to limit crop injury. It will detect these destructive insects lurking in certain portion of land and help its users to located them and do proper measures for its eradication. Helping the country's rice farmers and those people cultivating not only agricultural crops but also other plants, to lower the rate of massive plant destruction.

\section{Review of related literature and systems}

Agriculture or faming is the cultivation and breeding of animals, plants, and fungi for food, fiber, biofuel, medicinal plants and other products used to sustain and enhance human life. It plays a vital role in the society and gives huge factor in every nation's economy. Agriculture has been practiced ever since for food supply to every human need. There are various crops being cultivated by farmers and agriculturists, which serve as commodity not only for humans but also to any other living things. Circumstances are often faced by agriculturists whether it is natural occurrence or human cause.

Philippine agriculture is widely known around the globe. In fact, it is considered as a "mega diversity" when it comes on plant cultivation and farming. The country exports agricultural crops such as 
rice, corn, bananas, mango, etcetera. Thus, Philippines plays a vital role as one of the major supplier of agricultural products around the world, nevertheless, negative factors affecting the production of Philippine's agricultural products has huge drawback if not given attention immediately. The existence of destructive pests in agriculture yields economic and production loss to agricultural products if severe infestation is not prevented. It is evitable to provide solutions in order to further enhance agricultural practices and the agriculture itself.

Agriculture must be preserved and there must be continuous innovations and enhancement to support it. It will greatly benefit the entire country economically and for basic human needs. Farmer and agriculturist who are lacking for knowledge in some aspects must seek further knowledge and be guided by experts properly for them improve and adapts for today's innovation.

(Sowmyaa Guptaa, Gaurav Trivedi, 2016) Applications developed to help agricultural yield to increase are advancing whether it's on the field of robotics and technology based innovations. A mobile application developed by Indian developers helps its nation's current status in agriculture. E-KrishakMitra was developed to find efficient solution for the farmers that can help them in cultivating crops which can give them a better yield and are suitable as per the present weather conditions. Further it will act as a complete farmers' friend helping them in taking strategic decision by suggesting them about various issues related with the cultivation of crops such as soil's current nutrient status, irrigation needs, pest and disease identification, yield estimation etc. The said mobile application is efficient and user friendly which can further help Indian farmers to increase their harvest and prevent unwanted factors. It can help farmers and agriculturists to decide what crop is applicable depending on the current regional weather conditions. Nutrient level of soil can also be determined by using sensors in able to determine whether it is lacking or is in good condition. The daily irrigation requirement of the crops and irrigation schedule can be generated by the application. E-KrishakMitra can further accommodate its user to acquire information and suggestion regarding to the procurement of seeds of desired crops at an affordable rate in their region. Pests and diseases can also be determined by acquiring information from the assessment of the farmer to his farmland. The mobile application provides multiple services and information which allows its users to anticipate the success of his agricultural yields.

Technical Background

Hardware Requirements

- A mobile phone running Android Version 5.0 Lollipop and above

- $\quad$ Arduino MEGA

- Ultrasonic Sensor

- Bluetooth Module

Software Requirements

- Windows operating system version Vista and above

- Android operating system version 5.0 Lollipop and above

Application Development Requirements

- Android studio 3.0.1 for Windows (x64)

- Arduino IDE

\section{Analysis}

These comprises of the research design for the proposed project, the research locale of the study, sample of the population, sampling technique, instrument for data collection, and validation of the questionnaire.

Population and Locale of the Study

The figure above shows the research locale of the study (Daang Governor, Brgy. Makina, Naic Cavite)

\begin{tabular}{lll}
\hline Respondents & Number of Respondents & Percentage \\
\hline Farmers in Naic, Cavite & 10 & $50 \%$ \\
Farmers in Tanza, Cavite & 10 & $50 \%$ \\
Total & 20 & $100 \%$ \\
\hline
\end{tabular}

The sample consists of 20 individuals in Tanza and Naic Cavite along the "Daang Governor Highway" respectively. The respondents were chosen because of their knowledge and related experience on the field of agriculture and farming and has some knowledge regarding on the pest that infest their farmland.

Instrumentation

Related literature and works are the sources of data that will support the existence of the problems of this study. Furthermore, previous studies and research are also considered and critically examined. Through reading documents and continuous consultation to others' paper and studies, the researchers have come up with the presented problems of this paper.

Procedures

The researchers have used the descriptive method, which is literature, and deliberate surveys that includes current learning including substantive discoveries, and also hypothetical and methodological commitments to a specific theme in order to encase information gathered from its target area or research locale. The proponents gathered and looked various investigations, which utilizes strategies that are resolved before they start to outline at least one inquiries, at that point, they find and break down the examinations that identify with all the gathered inquiries.

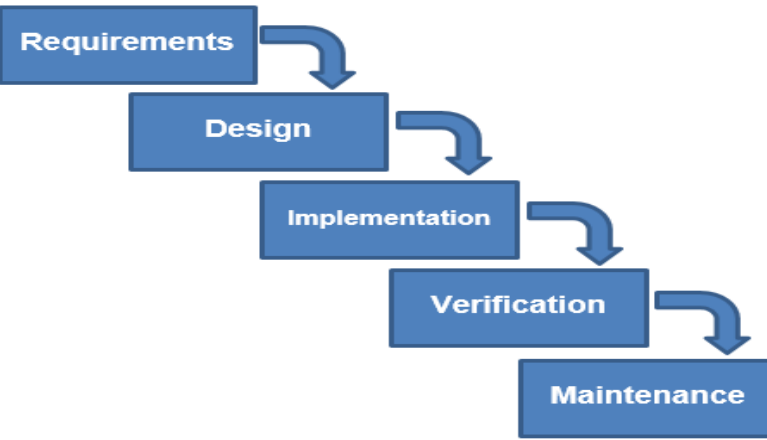

The model the proponents used for the gathering of data is the Waterfall Model. As defined in this model, stages were set as a series of sequential steps with the flow of time and information from left to right. The model defines the order of stages that will be delivered completely to the management at the end of each stage.

\section{Results and discussions}

\section{Analysis of Data}

The given answers of the respondents were able to validate the full capabilities of the proposed research topics by the proponents. Based on the given sets of data, each farmer has sets of difficulties when handling pest activities, hence, the creation of the research proposal. The problems encountered gives justification that a need for the development of the research entitled "NullPest: A Mobile Application of Agricultural Pest Locator Using SONAR Sensor Set-up".

Interpretation of Data

The given answer of the respondents has been one of the reason why the proponents have established the given statement of the problems on chapter 1 . Thus, the purpose of this study has been justified according to the answers of the respondents. "NullPest" will lessen difficulties and will give accessible information to its users.

\section{Conclusions and recommendations}

Summary of Findings

The following are the statement of the problems constructed by the proponents:

1) Only method used to determine the location of agricultural pests is by physical observation which gives difficulty in locating them 
2) Excessive use of pesticide is still a practice of farmers regardless of them knowing that it harms their health and the environment.

3) Some farmers are not familiar about the detailed information, characteristics and type of pest that infest their farmland.

The proposed mobile application has been developed and was able to aim its objectives. The ultrasonic sensor was able to locate rice pest which was demonstrated continuously. The pesticide monitoring module will help its user to monitor whether they've exceeded the normal usage of pesticide within a week and finally the Pest Information module that will aid its users by providing information regarding the existing rice pest that they're not aware about

\section{Conclusion}

Agriculture has been a vital necessity and most important factor that the Philippines should give importance to, moreover, one of the leading distributors of agricultural crops particularly on rice commodity all throughout the world. As a conclusion, "NullPest: A Mobile Application of Agricultural Pest Locator" will be a beneficial application for its users, most importantly, rice farmers for establishing a better agricultural reproduction. The objectives of the study was able to meet the expected results for a better agricultural community.

Base on the findings of the study, these set of conclusions are drawn:

1) The researchers concluded that the only method used by the farmers for locating agricultural pest is by means of purely observation only. Hence, there are no other ways in determining if there's any pest in a particular area in their farmland which gives difficulties to the farmers.

2) The researchers concluded that most farmers are practicing excessive usage of pesticide in which it gives harmful effects to the consumers. Moreover, some are not fully aware of its harmful effects and some are aware and yet they're still excessively apply those pesticides or chemicals.

3) The researchers concluded that some farmers lack on information regarding on what type of pest infests their farmland, and other information like its peak season, how does it affects the crops, and its widespread damage if not prevented immediately.

\section{Recommendation}

Further recommendations could be established for research enhancements. The connection of the whole application could be transitioned from Bluetooth to $\mathrm{WiFi}$ connection in order for additional information gathering to one of the module of the proposed study. Also, Passive Infrared motion sensor could be added to increase pest detection accuracy. The acquisition of the data provided by the ultrasonic sensor as it detects pest could be acquired through cloud database for better information management and could store current and past data for data comparisons.

\section{References}

[1] Barker R., and Molle F., 2004, Evolution of irrigation in South and Southeast Asia, (Comprehensive Assessment Research Report 5), Comprehensive Assessment Secretariat, International Water Management Institute, Colombo, Sri Lanka, 40pp.

[2] Chaudhary S., Raghuraman M., and Kumar H., 2014, Seasonal abundance of brown plant hopper Nilaparvata lugens in Varanasi region India, International Journal of Current Microbiology and Applied Sciences, 3(7): 1014-1017.

[3] Heong K. L., Wong L., and De los Reyes J. H., 2013, Addressing Planthopper Threats to Asian Rice Farming and Food Security: Fixing Insecticide Misuse, ADB Sustainable Development Working Paper Series No. 27 | August 2013Asian Development Bank, 6 ADB Avenue, Mandaluyong City, 1550 Metro Manila, Philippines.
[4] Hussain, I., (Editor) 2004, Poverty in irrigated agriculture in developing Asia: Issues, linkages, options and pro-poor interventions, Indonesia, International Water Management Institute, Colombo, Sri Lanka, 231pp.

[5] Krishnaiah N.V., 2014a, A Global Perspective of Rice Brown Planthopper Management I -- Crop-Climatic Requirement, International Journal of Molecular Zoology,4(2):9-18 (doi: 10.5376/ijmz.2014.04.0002).

[6] Bautista R. C. , Heinrichs E. A. and Rejesus R. S. (1984 ) Economic injury levels for the rice leaffolder Cnaphalocrocis medinalis (Lepidoptera: Pyralidae): insect infestation and artificial leaf removal . Environmental Entomology 13, 439 -443.

[7] Dale D. (1994) Insect pests of the rice plant - their biology and ecology, pp. 363 -485. In Biology and Management of Rice Insects (edited by Heinrichs E. A.). Wiley Eastern Limited, New Delhi.

[8] Dhaliwal G. S., Jindal V. and Dhawan A. K. (2010) Insect pest problems and crop losses: changing trends. Indian Journal of Ecology 37, $1-7$.

[9] Greenland D. J. (1997) The Sustainability of Rice Farming. CABI, Wallingford, UK. 288 pp.

[10] Heinrichs E. A. , Saxena R. C. and Chelliah S. (1979) Development and Implementation of Insect Pest Management Systems for Rice in Tropical Asia . ASPAC Food and Fertilizer Technology Center, Taipei. Extension Bulletin (Asian and Pacific Council, Food and Fertilizer Technology Center; No. 127).

[11] Horgan F. (2009) Mechanisms of resistance: a major gap in understanding planthopper-rice interactions, pp. 281 -302. In Planthoppers: New Threats to the Sustainability of Intensive Rice Production Systems in Asia (edited by Heong K. L. and Hardy B.). International Rice Research Institute, Los Banes.

[12] Kushwaha K. S. and Chand H. (1988) Effect of transplanting date and nitrogen level on the incidence of whitebacked planthopper in paddy. Indian Journal of Entomology 50, 12 -16.

[13] Mahajan G. and Sarao P. S. (2009) Evaluation of system of rice (Oryza sativa L.) intensification (SRI) in irrigated agro-ecosystem of Punjab. The Journal of Research ANGRAU 37, 1 -6. 